Revista Nacional de

Gerenciamento de Cidades

\title{
UBERLÂNDIA (MG) UMA CIDADE E SUAS METAMORFOSES
}

\author{
Cristiane Aparecida Silva Moura de Melo ${ }^{1}$
}

\author{
Laís Naiara Gonçalves dos Reis ${ }^{2}$
}

\begin{abstract}
RESUMO
O presente trabalho objetiva realizar um estudo das metamorfoses ocorridas na de cidade de Uberlândia (MG), mais precisamente no comércio desde a fundação da cidade na segunda metade do século XIX até a atualidade, esta analise foi realizada através de levantamento bibliográfico e documental. Através da confecção do trabalho foi possível averiguar que inicialmente o comercio funcionava com estabelecimentos que vendiam "secos e molhados", ou seja todos os tipos de mercadoria e com o decorrer do tempo e com a expansão da área central e a implantação da Estação Férrea da Mogiana o comercio passa a se diversificar e a cidade a ser um entreposto das mercadorias que vinham do estado de São Paulo para Goiás. Em decorrência disso a cidade cresceu no que tange o tecido urbano e a população. Com o decorrer do tempo surgiram os comércios especializados em diversas áreas, bem como a separação da venda de produtos agropecuários, de gêneros alimentícios, vestuário, dentre outros. Atualmente o comercio é diversificado e bem consolidado que atende a população tanto do município de Uberlândia e dos municípios vizinhos.
\end{abstract}

PALAVRAS-CHAVE: Metamorfose. Cidade. Expansão.

\section{UBERLÂNDIA (MG) A CITY AND ITS METAMORPHOSES}

\section{ABSTRACT}

This paper aims to conduct a study of the transformations occurring in the central city of Uberlândia (MG), more This paper aims to conduct a study of the transformations that occurred in the city of Uberlândia (MG), more

\footnotetext{
${ }^{1}$ Mestranda em geografia da Universidade Federal de Goiás - Campus Catalão. crisapa3179@gmail.com.br.

${ }^{2}$ Doutoranda em geografia da Universidade Federal de Uberlândia lais_ungida@hotmail.com .
} 


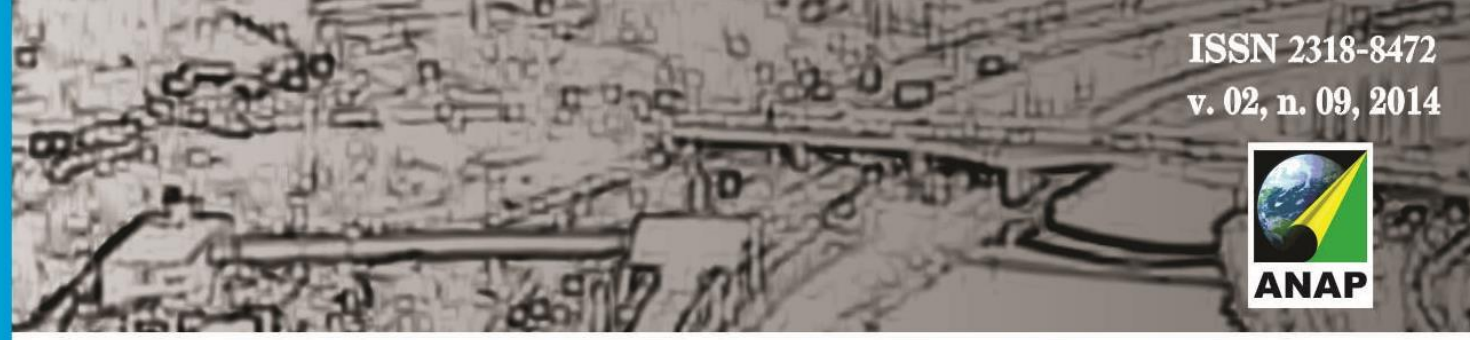

Revista Nacional de

Gerenciamento de Cidades

precisely in the trade since the founding of the city in the second half of the nineteenth century to the present, this analysis was conducted through a literature review and documentary. Through the building work has been possible to verify that the trade initially worked with outlets selling "wet and dry", ie all types of merchandise and with the passage of time and the expansion of the central area and the deployment of the Railway Station Mogiana the trade goes to diversify the city and to be a warehouse of goods coming from the state of São Paulo to Goiás. as a result the city has grown regarding the urban fabric and the population. With the passage of time the skilled trades emerged in several areas, as well as separation from the sale of agricultural products, foodstuffs, clothing, among others. Currently the trade is diversified and well established that meets both the population of the municipality of Uberlândia and neighboring municipalities

KEY-WORDS: Metamorphosis. City. Expansion.

\section{UBERLÂNDIA (MG) UNA CIUDAD Y SU METAMORFOSIS}

\section{RESUMEN}

Este trabajo tiene como objetivo realizar un estudio de las transformaciones que se produjeron en la ciudad de Uberlândia (MG), más precisamente en el comercio desde la fundación de la ciudad en la segunda mitad del siglo XIX hasta la actualidad, este análisis se realizó a través de una revisión bibliográfica y documental. A través de la creación de trabajo ha sido posible verificar que el comercio trabajó inicialmente con puntos de venta de "húmedo y seco", es decir, todo tipo de mercancías y con el paso del tiempo y la expansión de la zona central y el despliegue de la estación de tren Mogiana el comercio va a diversificar la ciudad y ser un almacén de mercancías procedentes del estado de São Paulo para Goiás. Como resultado, la ciudad ha crecido en relación con la trama urbana y la población. Con el paso del tiempo los comercios expertos surgieron en varias áreas, así como la separación de la venta de productos agrícolas, alimentos, ropa, entre otros. Actualmente, el comercio se diversifica y bien establecido que cumple tanto la población del municipio de Uberlândia y municipios vecinos

PALABRAS-CLAVE Metamorfosis. Ciudad. Expansión.

\section{INTRODUÇÃO}

A cidade de Uberlândia (MG) surge na segunda metade do século XIX, como um entreposto entre os estados de São Paulo e Goiás a qual servia como um local de parada dos tropeiros e comerciantes que transportavam mercadorias de um estado ao outro. Mas com o decorrer do tempo passa a ter um papel de grande importância no que tange o transporte de mercadorias com a implantação da estrada de ferro Mogiana. 


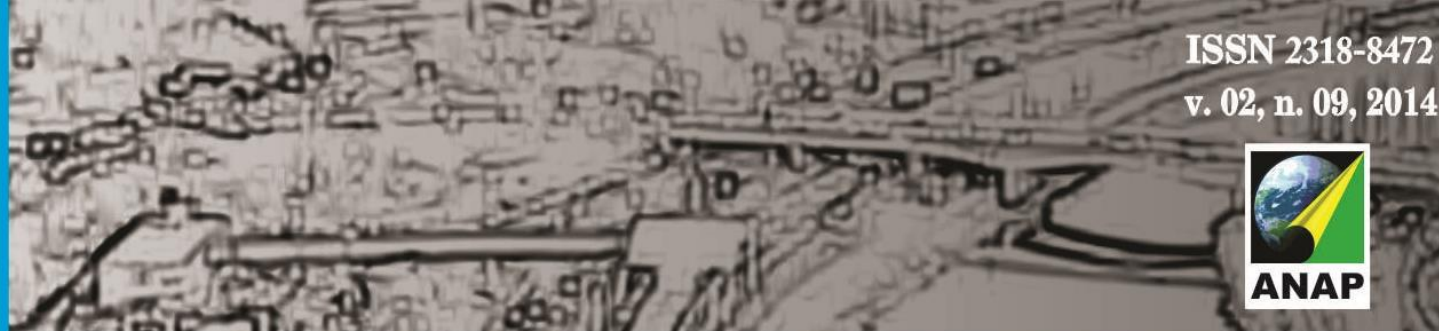

Revista Nacional de

Gerenciamento de Cidades

Com o decorrer do tempo a cidade se expande e o comercio cresce no sentido de atender aos recortes temporais e espaciais. Mas o maior marco do seu desenvolvimento se dá a partir da primeira metade do século $X X$, a fim de atender as necessidades da linha férrea.

Isso tornou a cidade um atrativo para investimentos em diferentes áreas da economia acarretando em um crescimento populacional e com o decorrer do tempo os serviços e comercio da cidade se tornaram um polo atrativo tanto para investimentos quanto o crescimento populacional ocasionado pelo processo de imigração o que configurou o município como o segundo maior do estado de Minas Gerais.

Quando há a comparação dentre o comercio do inicio do século $X X$ em relação ao de hoje pode-se averiguar que o mesmo se especializou tornando-se diversificado, bem como o setor de serviço.

Desta forma o artigo objetivou realizar uma retrospectiva do crescimento e metamorfoses ocorridas na cidade de Uberlândia desde que a mesma era um arraial até a sua atual configuração. Para a realização do mesmo foi realizado um levantamento bibliográfico bem como documental.

\section{DESENVOLVIMENTO}

A cidade de Uberlândia, que recebe este nome somente no século XX, surge como um arraial, na segunda metade do século XIX, como local de passagem dos tropeiros e comerciantes que transportavam mercadorias de um estado par o outo. Assim a cidade surge como um ponto de pouso para essas pessoas. Incialmente recebeu o nome de Uberabinha, devido esse motivo a configuração do espaço urbano foi cotidianamente pensada para que atendesse as necessidades das pessoas que o utilizavam. Lopes (2010) aponta que, os viajantes utilizavam Uberlândia como um local de descanso, pois traziam mercadorias provenientes do estado de São Paulo para comercializa-las no estado de Goiás. Desta forma, a 


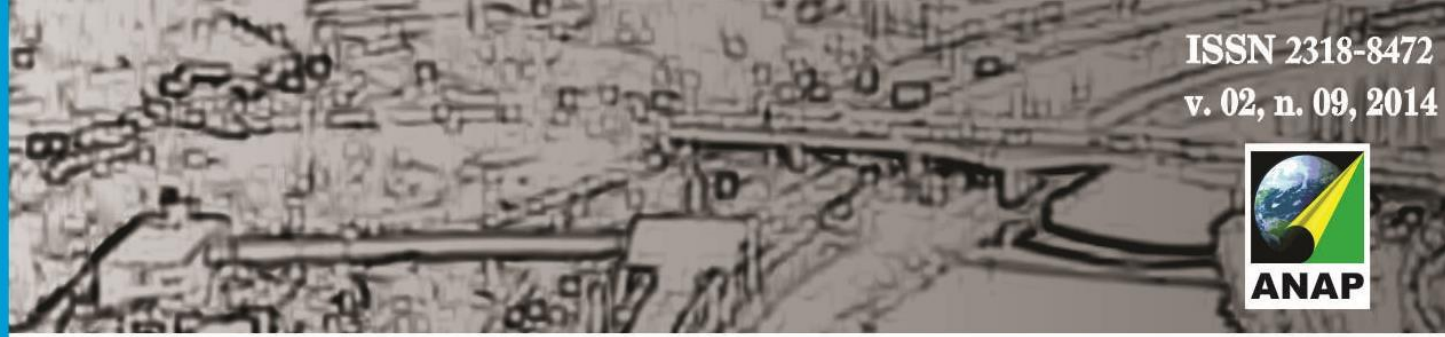

Revista Nacional de

Gerenciamento de Cidades

cidade não despertou interesse no processo de urbanização até o final do século XIX.

Neste período toda a cidade estava localizada na área central da cidade, o comercio era estritamente central, localizado onde hoje é conhecido como bairro Fundinho. Os estabelecimentos que ali se instaram eram poucos e que vendiam todo tipo de mercadoria os conhecidos "secos e molhados" e não possuía uma grande variedade de mercadorias $\mathrm{e}$ as pessoas das proximidades vinham periodicamente comprar todos os tipos de mercadorias que atendessem as suas necessidades.

No ano de 1895 a Companhia Mogiana de Estradas de Ferro chegou a Uberlândia fazendo da cidade um polo de atração para uma serie de atividades ligadas a economia, como destaca Lopes (2010), então, a cidade de Uberlândia (MG) passa a se tornar atrativa para a instalação de comércios e pequenas fábricas a partir de meados do século $\mathrm{XX}$, quando passa por um processo de desenvolvimento com a implantação da estrada de ferro Mogiana, tornando-se um polo de atração.

Em decorrência disto criada a estação ferroviária na área central mais precisamente onde hoje está localizada a Praça Sérgio Pacheco. Dando inicio assim a um lento processo de expansão da área comercial em direção a nova estação ferroviária que ocorreu de forma planejada, que pode ser confirmado nas avenidas Floriano Peixoto e Afonso Pena, que possuíam uma forma retilínea, com iluminação publica, calçamento, pois as mesmas ligavam a cidade velha para a sua nova área de expansão. Isso demonstra uma preocupação com o processo de urbanização a cidade. Como demonstra a figura 1 que retrata a planta da cidade do ano de 1898. 


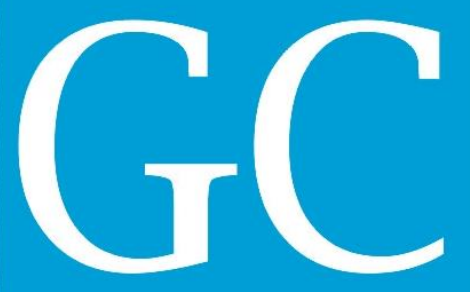

Revista Nacional de

Gerenciamento de Cidades

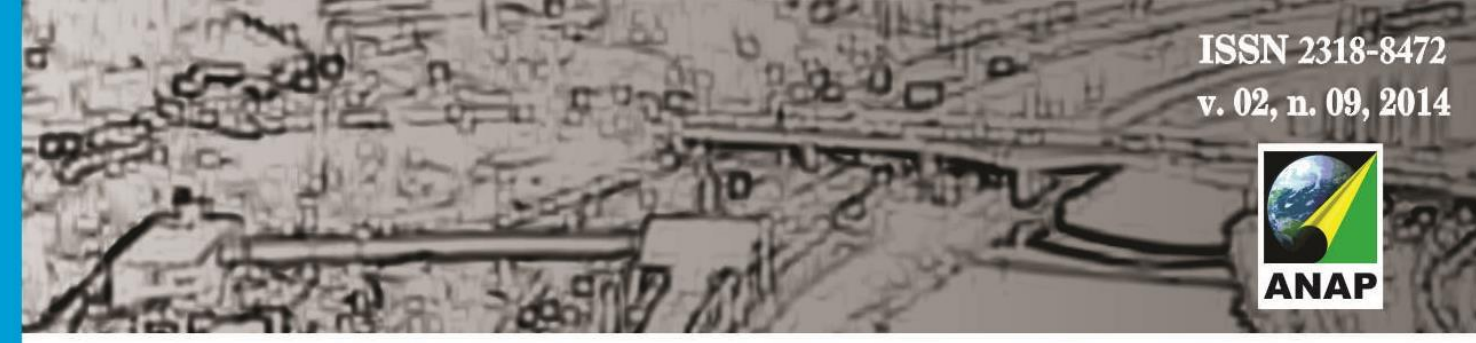

Figura 1: Planta da cidade de Uberlândia do ano de 1898

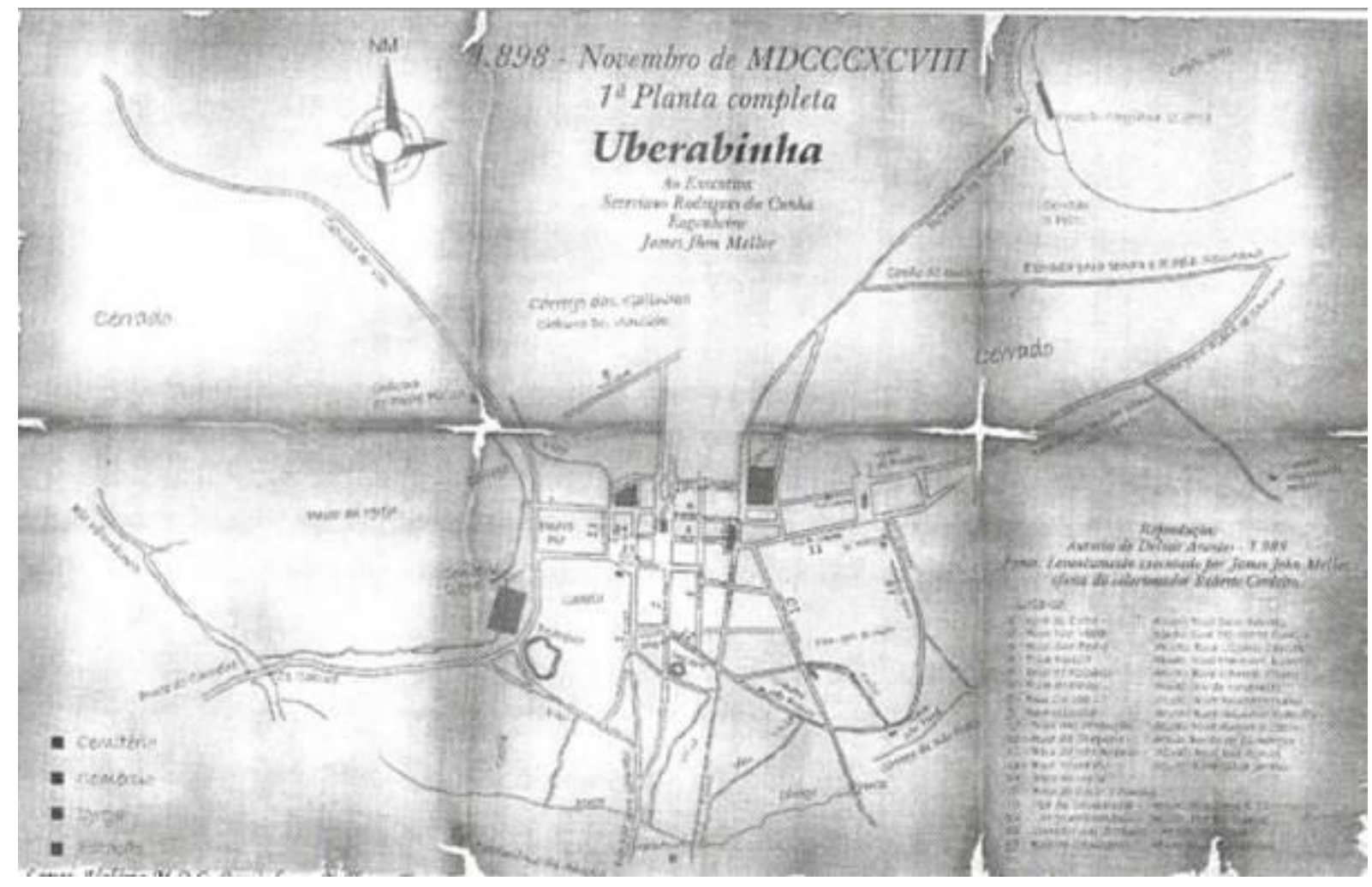

Fonte: LOPES, Valeria Maria Queiroz Cavalcante, 2010

Ainda no que tange a questão do planejamento é possível observar nas plantas da cidade, a partir da década de 1910, é possível verificar desde o inicio de seu planejamento, há a preocupação dos governantes em realizar projetos voltados ao ordenamento espacial. Observa-se, ainda, nas primeiras imagens cartográficas da cidade, que as ruas eram em forma de tabuleiro o que permitia a fluidez e a mobilidade das pessoas que por ali passassem como demostra a figura 2. 


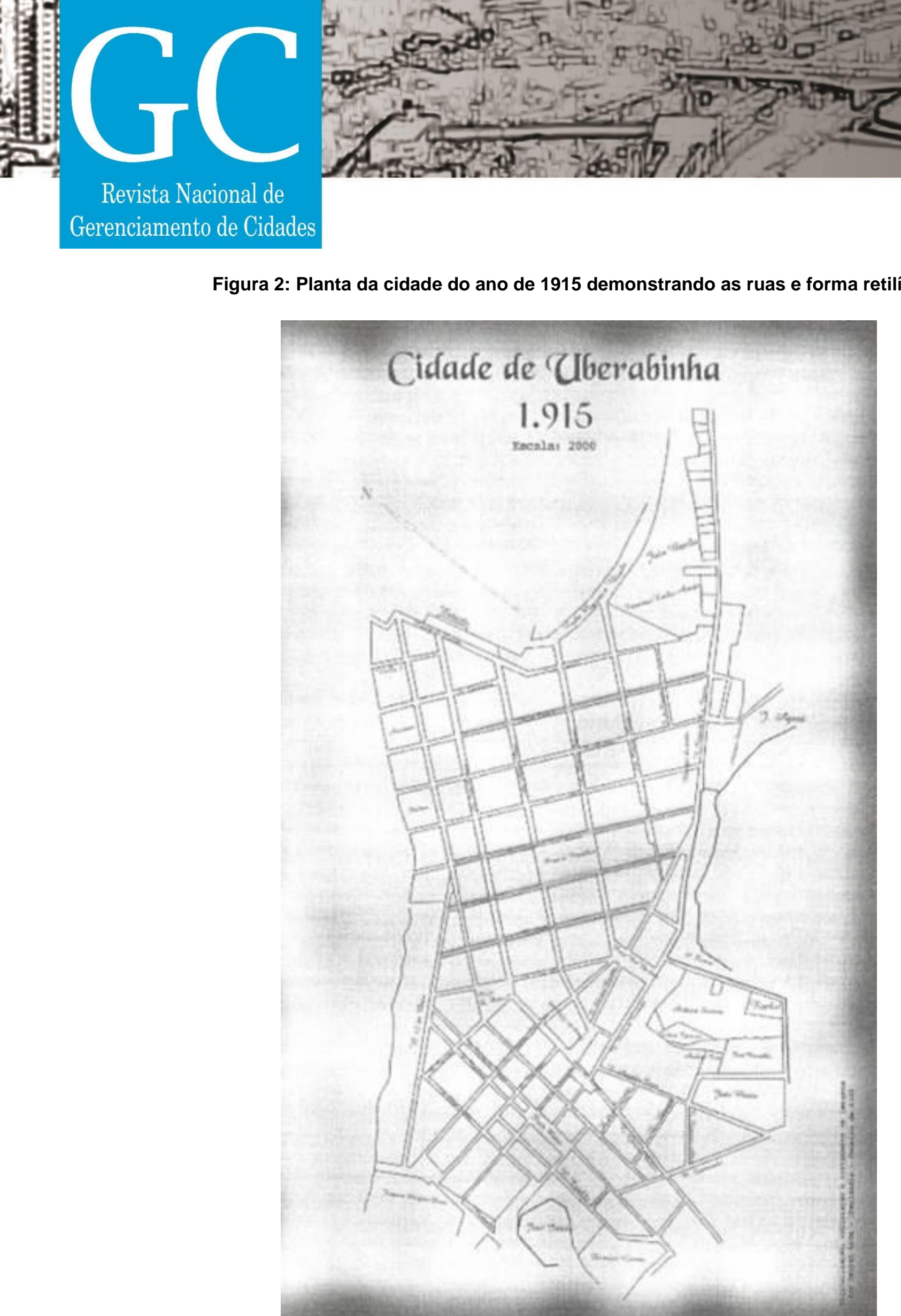

Fonte: LOPES, Valeria Maria Queiroz Cavalcante, 2010 


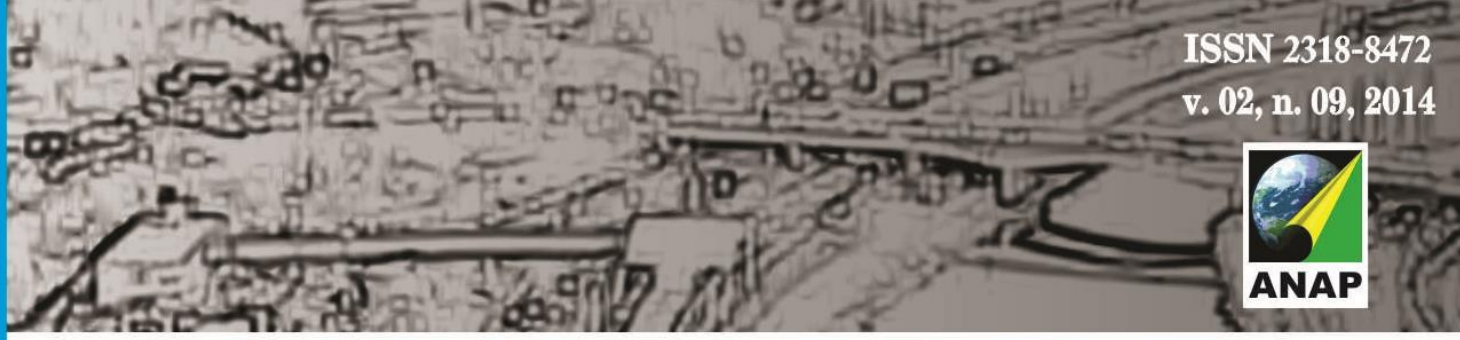

Revista Nacional de

Gerenciamento de Cidades

Essa evolução acarretou em um aumento da população. De acordo com Lopes (2010),

\begin{abstract}
Os primeiros eventos econômicos e religiosos que nortearam a organização social do município tem sua importância histórica por terem sido o embrião da sociabilidade urbana. [...] a fisiologia de Uberlândia está assentada nestes primitivos interesses econômicos, financeiros e religiosos que imprimiram no território urbano a sua geografia. Os discursos oficiais denotam a importância atribuída, já naqueles primeiros anos de emancipação, à observação da completa simetria do serviço de ornamentação e às questões econômicas que viabilizariam o tão propalado progresso, não se deixando impressionar pelo fato de ter por vizinhos outros municípios que, politica e/ou economicamente, exerciam maior importância no cenário regional. (LOPES, 2010 p. 21)
\end{abstract}

Desta forma inicia-se uma crescente articulação de Uberlândia (que recebe este nome na década de 1940) com as cidades do entorno. A crescente articulação com as cidades e os povoados da região fez com que o agente atacadista assumisse o papel principal da divisão territorial do trabalho na região. $O$ crescimento da importância do comércio em Uberlândia também se deve ao fato de a industrialização não ter conseguido se desenvolver com eficácia na cidade, atuando basicamente, no setor de beneficiamento de matérias-primas, como 0 arroz (SOARES, et al, 2010 p.166). Outro aspecto importante que levou ao impulso do crescimento da cidade foi a construção da nova capital Brasília, que colaborou na sua consolidação como um centro atacadista, já que a mesma é um entreposto entre os estados de São Paulo e Goiás. Também devido a modernização da agropecuária, conforme afirma Soares, et al (2010),

A construção de Brasília foi outro importante fator no aumento da importância de Uberlândia na rede urbana e na sua consolidação como centro atacadista. Foram criadas, assim, novas "praças" que o comércio atacadista, desta cidade, pôde abastecer, levando à criação de empresas uberlandenses que, hoje, são nacional e internacionalmente conhecidas neste ramo, como Martins, Arcom e Peixoto. [...] o processo de modernização agropecuária teve inicio no pós Segunda Guerra Mundial, com a chamada Revolução Verde, que visava aumentar a produção e a produtividade agrícola mundial, pela aplicação de desenvolvimento tecnológico, melhoramento genético e outros. No Brasil esses efeitos passaram a ser sentidos, sobretudo, após a década de 1960, devido aos projetos políticos de modernização do país, durante o governo Juscelino Kubistschek (1955 - 1960). (SOARES, et al, 2010 p. 166 - 167) 


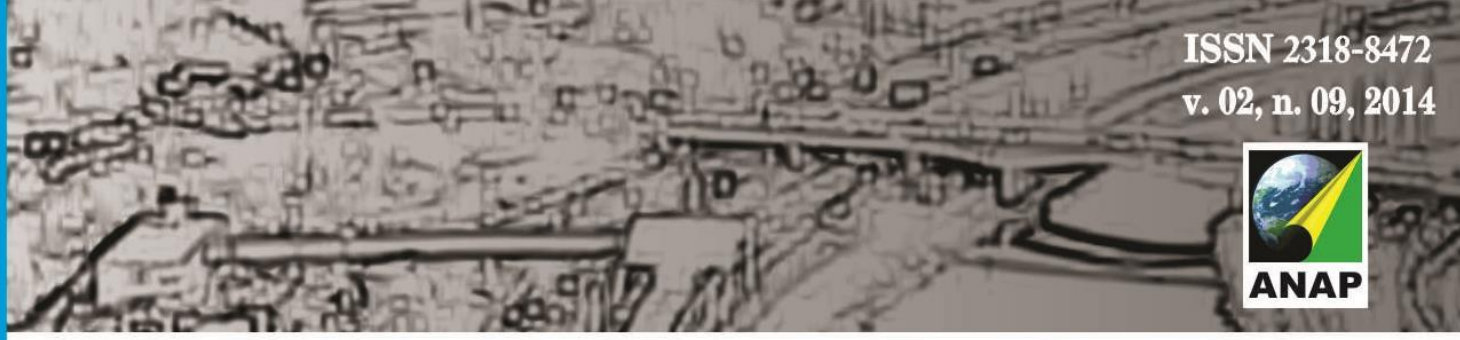

Revista Nacional de

Gerenciamento de Cidades

Entre os anos de 1950 a 1980 a cidade sofre uma série de modificações na sua morfologia, juntamente com a implantação de estradas de rodagem e como consequência disso, também passa por mudanças no que tange cultura, economia e sociedade, como expõe Soares, et al (2010)

Entre os anos 1950 e 1980, Uberlândia passou por transformações econômicas, sociais e culturais nunca antes vivenciadas por sua população. No que diz respeito à sua forma urbana, fruto de desenvolvimento das relações socioespaciais, as mudanças foram significativas, pois foram criados os loteamentos de alto poder aquisitivo, os arranha-céus, os conjuntos habitacionais, o asfalto, o neon, a televisão, o supermercado, os centros comerciais, o Distrito Industrial, a universidade federal, entre outros. Ao mesmo tempo, intensificaram-se também as contradições nas formas de ocupação do solo urbano, tais como: expansão para as áreas distantes do centro, densificação do núcleo central e problemas de trafego e transporte, que exigiram da administração municipal a elaboração de um plano urbanístico, em que fossem encontradas alternativas para tais problemas. (SOARES, etal, 2010 p. 172)

Esse processo também acarretou um grande desenvolvimento da cidade de Uberlândia, caracterizada como cidade de porte médio. Segundo Filho e Alves (2006), o forte desenvolvimento das cidades médias possibilitou a ocorrência de transformações em âmbito interurbano, como a valorização das cidades médias perante a hierarquia urbana; e de modificações na estrutura intra urbana dessas cidades, pela instalação de novas centralidades, as quais são representadas pelos subcentro, eixos comerciais, áreas especializadas e shoppings centers.

Segundo o censo do IBGE realizado no ano de 2010, Uberlândia conta com 604.013 mil habitantes, o que a torna a segunda maior cidade do estado de Minas Gerais. Atualmente a cidade conta com centros universitários que desenvolvem pesquisas em diversas áreas da tecnologia (inclusive para a Petrobrás), universidades particulares, um grande parque industrial contando com metalúrgicas, mecânicas, moveleiras, borracha, curtumes, químicas, produtos farmacêuticos, plásticos, materiais de limpeza, calçados, produtos alimentícios, bebidas, fumo, tecidos, gráficas e construção civil.

A malha urbana se desenvolve para os setores norte, sul, leste e oeste 0 que acarreta em um crescimento urbano. É ainda um polo de atração de 


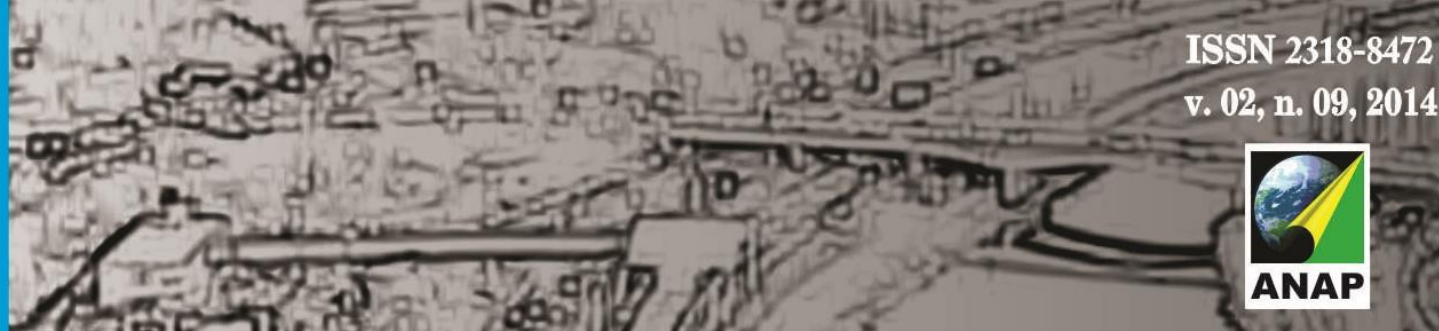

Revista Nacional de

Gerenciamento de Cidades

investimentos privados além possuir centros de Call Center, desenvolvendo-se no setor terciário de serviços especializados. Destaca-se também no setor agrícola com uma grande produção de soja e café.

\section{CONCLUSÃO}

A partir da construção do trabalho foi possível averiguar que as cidades surgem a partir das necessidades importas por um determinado recorte temporal. Assim a cidade de Uberlândia (MG) surge na segunda metade do século XIX, servindo de um local de descanso para os tropeiros que percorriam o estado de São Paulo em direção ao de Goiás levando diversos tipos de mercadorias.

Desta foram surge um pequeno arraial caracterizado por ser essencialmente agrário, com um pequeno comercio no bairro Fundinho (mais antigo da cidade). Mas com o decorrer do tempo a cidade se torna um entreposto de grande importância para ligar um lugar ao outro e assim em 1895 foi implantada a ferrovia Mogiana, cuja estação ferroviária foi instalada a onde hoje é a praça Sérgio Pacheco e o Terminal Central, que é de fundamental importância tanto para o desenvolvimento da cidade quanto do comercio e setor de serviços.

A partir disso a cidade se expande para todos os setores, bem como o surgimento de novos comércios a área central, além da abertura de novas avenidas como a Afonso Pena. Nesse momento é possível averiguar a preocupação dos governantes em realizar um desenvolvimento planejado da malha urbana que estava em expansão.

O que é importante ressaltar que a cidade surge como um local de descanso, ou seja, um entreposto entre os estados de São Paulo e Goiás e que com o decorrer do tempo passa a ter um importante cunho comercial. E com o decorrer do tempo foram se instalando diversos tipos de comércios e serviços a fim de atender as novas necessidades que surgiam. Assim hoje Uberlândia é a segunda maior cidade do estado de Minas Gerais, sendo um centro de referencia para as cidades do entorno. 
